\title{
Design and Building of a Fast-acting and Intelligent Lifting System of Submerged Objects
}

\author{
Mahmoud Salari', M. B. Zarouj Shabani² and M. Hemmat Esfe ${ }^{3^{*}}$ \\ 'Mechanical Engineering Department, Imam Hussein University, Tehran, Iran; msalari@ihu.ac.ir \\ ²Gilan University, Rasht, Iran; mbshabani1390@yahoo.co.uk \\ 3Department of Mechanical Engineering, Najafabad Branch, Islamic Azad University, Isfahan, Iran; \\ m.hemmatesfe@gmail.com
}

\begin{abstract}
In this paper, a new lifting system for rising of the seabed submerged objects is proposed. The processes of design and building are also presented in detail. Fast-acting, intelligent, easy-performing and portability are most important characteristics of the new system. The required force for most of the existing lift systems is usually provided by creating a hollow-water volume, or a gas-filled bag, under the water. Based on the Archimedes' law, an upward buoyancy force produces at these conditions. A compressed air capsule is usually used for filling the bag in most of the existing methods. Big and heavy components of those systems cause some operating difficulties. Also, the presence of a frogman is a necessity for those systems. It is obvious that the depth of the presence for a frogman is limited. It is very harmful for a frogman to be present at the water depth of more than about 40 meters without using of the pressure chambers and more safety equipments. In order to deduce the above matters, a new design for a lifting system is proposed in this research. In this system, instated of using a compressed air system, combustion of a solid-fuel substance with a controlled condition and cooling of the gaseous products, provides the required gas for filling the bag. The most important applications of this new system can be where shortening of the operation time is vital, such as at naval, safety and emergency subjects of the marine engineering applications.
\end{abstract}

Keywords: Fast-acting Lifting System, Gas Generator, Seabed Submerged Bodies.

\section{Introduction}

One of the important subjects in the marine engineering is recovering the submerged objects from the seabed. Lifting of precious equipments submerged in the seabed, sunken ship cargos, facilities of marine wells, submerged naval tools such as marine mines and the sampling devices of ocean biologists, are some application issues that should take into account during the design of lift systems [1-2]. There are currently some existing methods to lift the commercial objects from the seabed. Generally, for lifting the submerged bodies from the depths up to about 40 meters, it is usual to use from cranes, compressed air systems, cable joints and connections, air bags, safety equipments and in presence of frogmen. For more than about 40 meters in depth, it should be also considered more special equipments such as the pressure chambers and so on. It is obvious that the installation and operation of the above equipments requires a lot of time and cost. Complexity of the existing methods was a base for proposing a new fast-acting and intelligent lifting system. At the proposed system, by changing the phase of a solid substance to its gaseous state, resulted from combustion in subject to other chemical materials, the required gas for filling the bag is produced. After that, the filled-bag provides the sufficient buoyancy force for lifting the attached objects up to the sea level.

Some of the expected characteristics of the new system respect to the existing designs are as the followings: 1) no need to frogmen 2) no limit in working depth 3) lack of any big and heavy components such as compressed air

* Corresponding author:

Mahmoud Salari (msalari@ihu.ac.ir) 
system 4) fast-acting and intelligent 5) appropriate for especial goals such as military uses and etc.

In the variety of the applications of this kind of lifting system, it is also worth to mention that it can be installed as safety system on some important equipment of ships that have a risk of sinking, so the lifting system operates automatically after sinking and come up them to sea surface [3].

\section{Specifications of Prototype Design}

A prototype was defined for consideration of design and building requirements of the proposed lifting system. The general specifications of this prototype are listed in Table 1.

The target is lifting a solid body with about $200 \mathrm{~kg}$ of weights from the sea depth of $30 \mathrm{~m}$ within the time of less than $5 \mathrm{~s}$. In this regard, the important considerations in the design of new system are as the followings:

1) The system is built as a package with small volume and little weight.

2) No need to external mechanical or electrical joints.

3) No need to presence of frogmen.

\section{Components and Subsystems}

The new lifting system consisted of different parts and subsystems. They are as the followings:

1) Folding bag with suitable hydrodynamic characteristics.

2) Gas generator system.

3) Intelligent command system.

Table 1. General specifications of the required lifting System

\begin{tabular}{ll}
\hline The maximum weight for & $200 \mathrm{~kg}$ \\
lifting & $30 \mathrm{~m}$ \\
The maximum operation depth & $15^{\circ} \mathrm{C}$ \\
The ambient water temperature & Compressed liquid \\
& $\begin{array}{l}\text { capsule or solid-fuel } \\
\text { motor } \\
\text { System of filling the bag }\end{array}$ \\
& $10 \mathrm{~m} / \mathrm{s}$ \\
Rising speed of the payload & Timer, pressure and \\
command system & magnetic pressure etc. \\
\hline
\end{tabular}

4) Mechanical systems for control of relative pressure inside the bag.

\subsection{Folding Bag and Hydrodynamic}

\section{Characteristics}

For moving-up of the submerged object to the sea surface, a lift force is needed. The new system utilized from a buoyancy force that is produced by gas-filled bags. The value of the buoyancy force is depended to the volume of gas-filled bag and the density of the water. The gas-filled bag shape is also designed hydrodynamically, in a way to have minimum drag (resistance force against motion of solid objects within a fluid). So, it can move upward in more speed [5].

It must be noted that the buoyancy force of the gasfilled bag can lift an object with a mass of equal to the mass of water with the bag volume.

This bag is made of rubber and PVC and it can be folded and placed as a package in its cover (Figure 1). In command time, a protective system is opened and the bag is released. All of these operations should take a time less than about $1 \mathrm{~s}$.
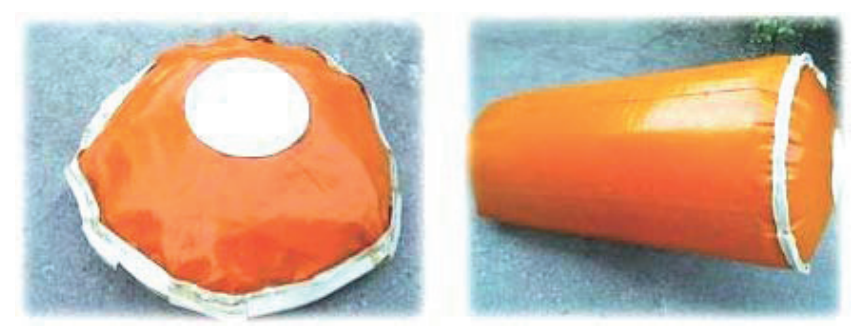

Figure 1. Empty and filled (inflated) forms of the bag.

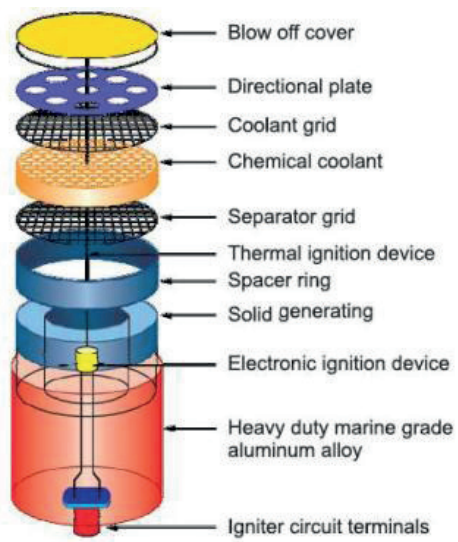

Figure 2. Components of the solid-fuel gas generator and its cooling system. 


\subsection{Gas Generator System}

Gas generator system is working by two mechanisms with different functions:

1) Producing the gas based on discharging from a pressurized $\mathrm{N}_{2}$ liquid capsule.

2) Gas production by combustion of a solid fuel accompanied by a gas cooling system.

Components of the solid-fuel gas generator system and its cooling system are shown in Figure 2. Both of the gas generator systems (Figure 3) are required to produce gas instantly after the command. Explaining about this function is exceeding the field of this paper [6].

\subsection{Command System}

Once the electronic board (controller) has received a command from an external commander, that can be an automatic sensor, timer or operator command, the actuators that installed within the center of gas-bag will send an electric signal to a mini solid-propellant motor (inflator). After that the motor combust rapidly and release the gaseous-products. This gas enters the bag after passing through a convergentdivergent nozzle, a filter and gas cooling system.

Minimizing the time for filling of the bag is one of the most important requests. So, this system is designed as to do this within less than 1s. Measurement of the gas- pressure during filling of the bag is difficult, but it is estimated that the interior pressure (relative to the outside pressure) of the bag was more than about 100kpa. The gas-filled bag can be different in terms of the request, design, shape, moving-up speed and etc.

Here, the starting system and intelligent command is provided by an electronic board (Figure 4). Receiving signal from sensors, processing and issuing the start command to the blower are some functions of the board. In this design, receiving signal for starting system is done in two ways:

1) Mechanically or by mechanical timers, pressure gauges or etc.

2) Electronically and by different kinds of electronically sensors [7-9].

After receiving the command signals by one of mechanical or electronically systems, the processing board analyzes them and finally the command is issued by it. By issuing start command, the blower works and reaches the volume and pressure to their pre-defined amounts. Now, the required Buoyancy force is provided and the lifting system will be ready to move the attached objects upward.

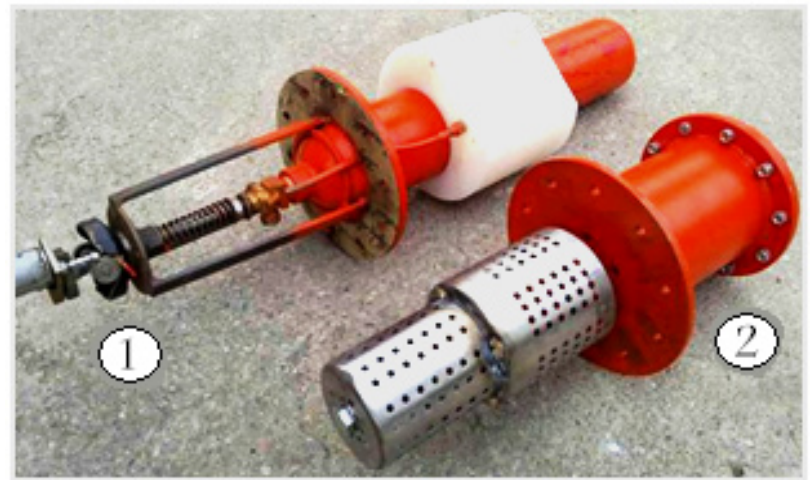

Figure 3. 1) Gas generator using liquid capsule 2) Solid-fuel gas generator accompanied by a cooling system.

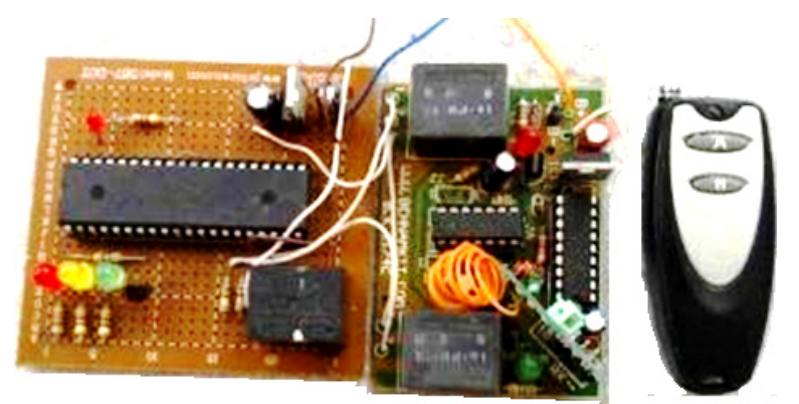

Figure 4. Timer electronic board together with a radio control.

\subsection{Control of Bag Pressure during Upward Motion}

Once the bag is filled by gas in the sea depth, it is exposed to both of the internal pressure produced by the blower, andthe external hydrostatic pressure of water. It is obvious by moving toward the sea surface, the external pressure reduces gradually by decreasing in the water depth, while the internal pressure of the bag is constant. This can increase the relative pressure (respect to outside) inside of the bag and may cause to tear the bag. In order to prevent from this, we should use a system to make constant the relative pressure between inside and outside of the bag. Using a safety valve, chosen for the required relative pressure, the relative pressure of the bag is controlled to be constant during lifting.

\section{Hydrodynamic Design Considerations for the Bag}

The gas-filled bag can be considered as a solid body during its upward motion. While the bag moves upward, a resistance force, generates by interaction and contact of the body with water that called drag force, exerts on the body and reduces its speed. Selecting a suitable hydrodynamic 
form (shape) of the filled-bag is one of the important subjects for reducing the drag force and shortening the lifting time from seabed to the surface. So, in this research it is attempted to choose a good form for the prototype.

The Resistance force, $F_{D}$ (drag) is consisted of the friction drag and the pressure drag. Of course, the total drag coefficient $C_{D}$ for such objects also depends to the Reynolds number. The drag coefficient can be expressed as:

$$
C_{D}=\frac{F_{D}}{\frac{1}{2} A \rho V^{2}}
$$

where, $A$ is the area of the cross section surface at the largest diameter of the bag; $V$ is the upward speed of the body and $\rho$ is the density of sea water. At low speed regime (or low Reynolds numbers), no wake zone is appeared or wake region will be small. In these cases, friction drag is dominated and total $C_{D}$ is most influenced by $C_{F}$. Increasing the Reynolds number may cause a flow separation region and a larger wake zone may be appeared behind the body. This separation region affects directly on the total drag coefficient, so we have:

$$
C_{D}=C_{D . P}+C_{D . F}
$$

The magnitude of each component of total drag of the body, the friction drag, $C_{D F}$ and the pressure drag $C_{D P}$ is depended to the profile of nose and tail. In this research, the effects of surface curvature or pressure gradient on the pressure drag and also the mechanisms that can control the above factors for reducing the total drag have been investigated hydrodynamically. In Figure 5 the streamline effects of the body forms on the drag coefficient are shown schematically. It is obvious that the selection of a suitable form for nose and tail can be of great importance in design process of such systems [10]. Details for the connection of gas generator systems to gas-filled bags for both of the liquid capsule and solid-fuel systems are shown in Figure 6.

Generally, it tries to minimize the total drag force by reducing separation zone. Based on the fluid dynamics, negative flow gradients, $d p / d x<0$, on the body surface cause to reduce the separation region. Therefore, it is worth to reduce the amount of $\mathrm{dp} / \mathrm{dx}$ in the rear part of the object by increasing the tail region of body, but increasing the length of the tail accompanied with increasing of the friction drag. Thus, an optimized length should be found so in which the sum of pressure drag and friction drag are at minimum.


(c)

(d)

Figure 5. The importance of streamlining in reducing drag of a body (CD based on frontal area): (a) rectangular cylinder; (b) rounded nose; (c) rounded nose and streamlined sharp trailing edge; (d) circular cylinder with the same drag as $\operatorname{case}(\mathrm{c}) .[11]$

\section{Estimating of the Steady State Upward-velocity}

To estimate the steady state velocity of body at the upward motion (Figure 7), the balance equation of forces is derived for the object. The vertical forces exerted on the body are as the followings:

1) Total weight of the set, $W=M g$

2) Buoyancy force, $F_{B}=V \times \rho_{\text {water }}$

3) Hydrodynamic drag force, $F_{D}=C_{D} \frac{1}{2} A \rho V^{2}$

$$
\sum F_{\text {vertical }}=M a \quad \Rightarrow \quad F_{B}-F_{D}-M g=M a
$$

At the steady conditions of upward motion, the body reaches to a constant velocity, called as the limit velocity, so its acceleration vanishes; $a=0$, then

$$
F_{B}-M g=C_{D} \frac{1}{2} A \rho V^{2}
$$

According to the mentioned properties for the studied system, the upward limit velocity for such as system are including as [10]:

$$
\begin{gathered}
A=\frac{\pi^{2}}{4}=0.282 \mathrm{~m}^{2}, \quad m g=200 \mathrm{~kg} \times 10 \mathrm{~m} / \mathrm{s}^{2}=2000 \mathrm{~N} \\
F_{B}=0.4 \mathrm{~m}^{2} \times 1000 \mathrm{Kg} / \mathrm{m}^{3}=400 \mathrm{~kg}=4000 \mathrm{~N} \\
F_{D}=C_{D} \frac{1}{2} A \rho V^{2}=0.15 \times 0.5 \times 0.282 \times 1000 \times V^{2}=21.15 \mathrm{~V}^{2} \\
4000-2000=21.15 \mathrm{~V}^{2}==\mathrm{V}=9.72 \mathrm{~m} / \mathrm{s}
\end{gathered}
$$


It must be noted that the amount of $\mathrm{Cd}=0.15$ is used in the calculations [11].

\section{Structural Design Considerations for the Bag}

From structural point of view, the bag is a pressure vessel. So, it must have enough strength against the internal pressures. Based on the hydrostatic laws for fluids, for each 10 meters of depth from the sea surface, 1 bar is added to the ambient pressure. So if we decided to inflate the flexible bag, for example in the depth of $30 \mathrm{~m}$, it needs an absolute pressure higher than about 3 bars. Also during moving up of the body with a steady state velocity V, the highest value of the hydrodynamic pressure acts on top nose of the bag. This pressure equals $P_{0}$ and called as the stagnation pressure. So, the minimum amount of the pressure inside the bag should be a little more than stagnation pressure occurred during upward motion. It is about 4 bar for our target.

At the depth of target, $30 \mathrm{~m}$, the difference between the internal and external pressures of the bag is about lbar, so it doesn't cause any structural problem for the bag. During moving the body toward the sea surface, the difference of the internal and external pressure increases gradually by decreasing the external pressure. If the bag was designed structurally for supporting 1 bar, this increased pressure may cause to tear it. To deduce this problem in the new lift system, it is utilized from a safety valve for adjusting the pressure difference. It works based on discharging the net gases from bag during upward motion, so the relative pressure of the bag will set to be constant. Utilizing from this especial method not only can control the value of the relative pressure between the bag and water, but also the exhaust gases can directed over the body surface to reduce the friction drag. This is based on the fact that one of drag reduction methods in water is injecting air- micro bubbles within the boundary layer near the body surface [11].

In this research, a new technique is also proposed for uniform distribution of the exhaust gases over the external surface of the bag. At the this technique, a fine warp and woof cloth can be select for the bag so its pores are opened by relative pressure of $1 \mathrm{bar}$, and at during the moving up the gas escapes from these fine openings. By this method, not only the relative difference of the bag respect to environment will be constant but also the gas flows over the surface of the bag reduce the friction coefficient.

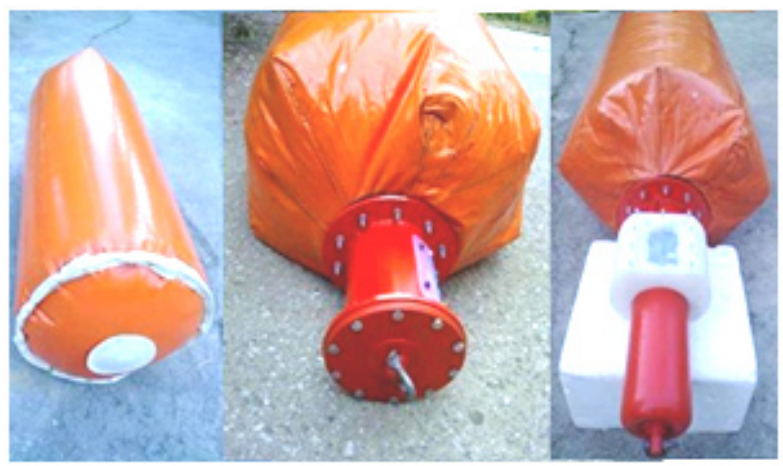

Figure 6. The connections of gas-filled bag to gas generator system for both of the liquid capsule and solid-fuel system.

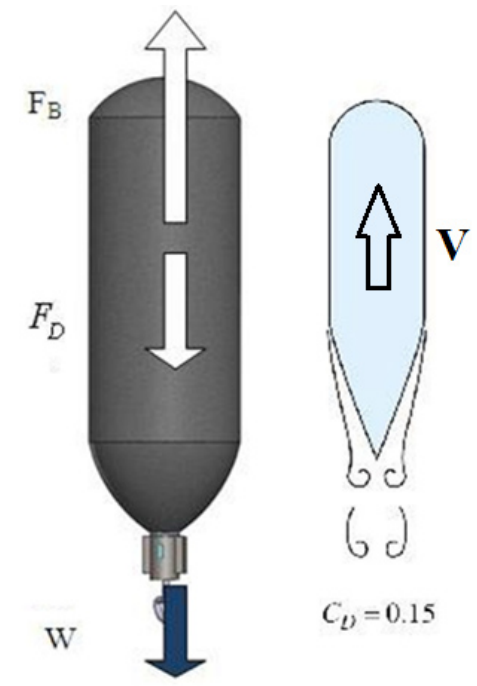

Figure 7. Forces on the gas-filled bag during moving-up with constant velocity.

\section{Discussion and Conclusion}

The conventional lift systems have some major limitations as; the working depth, the need for many types of equipments, necessity to frogmen and have a time-consuming operation [3]. In addition, the functional problem of the frogman under water, especially in depth exceeds about $30 \mathrm{~m}$, increase the difficulties to use them [4] (see Figure 8). It must be noted that the lift systems of the compressed-air capsules have more commercial uses in marine applications yet [12-13].

In order to deduce from the operational difficulties and the complexity related to their subsystems, a new method is introduced and explained in this paper. The new lift system has some unique advantages for marine applications. Some of the functional parameters in the existing systems and the new system are compared in Table 2. It doesn't 


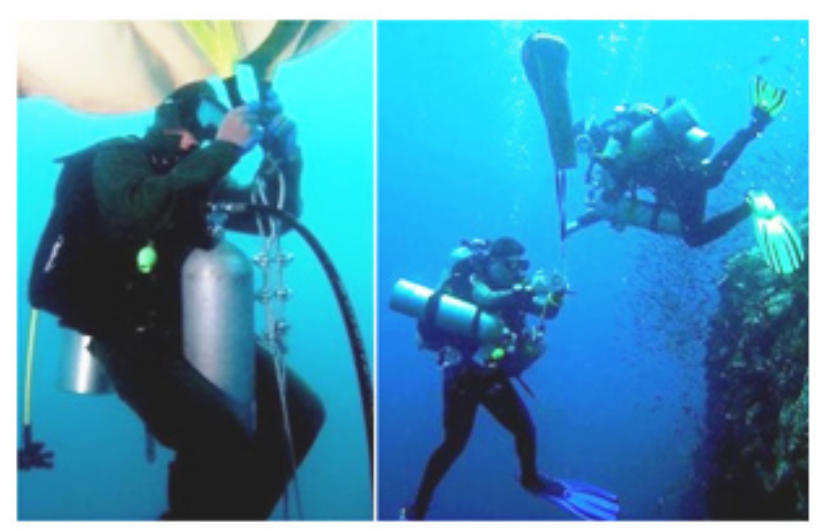

Figure 8. Launching difficulties of the frogmen in sea depth by compressed-air lifting systems.

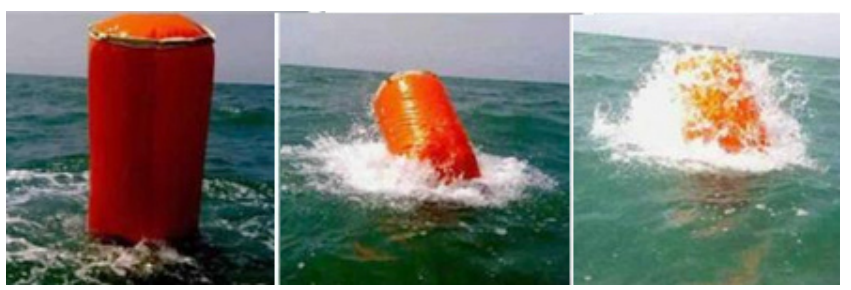

Figure 9. Coming up of the prototype to the sea surface using the new lifting system.

Table 2. Comparison of the functional parameters in the existing and new systems

\begin{tabular}{|c|c|c|}
\hline Parameter & $\begin{array}{l}\text { The existing } \\
\text { systems }\end{array}$ & The new system \\
\hline Depth of operation & Limited & No limit \\
\hline $\begin{array}{l}\text { The minimum staffs for } \\
\text { operation in the depth }\end{array}$ & 1 person & No one is required \\
\hline Time for filling the bag & About 2 hours & Less than $1 \mathrm{sec}$ \\
\hline Weight & $\begin{array}{l}\text { Rather heavy } \\
\text { (many launching } \\
\text { equipments) }\end{array}$ & Light \\
\hline $\begin{array}{l}\text { The mass-ratio of The lift } \\
\text { system to payload }\end{array}$ & Rather much & Little \\
\hline $\begin{array}{l}\text { The volume-ratio of the } \\
\text { lift system to its safety } \\
\text { system }\end{array}$ & Rather much & Little \\
\hline Safety & $\begin{array}{l}\text { Low ( launching } \\
\text { problems by } \\
\text { frogman) }\end{array}$ & high \\
\hline Maneuverability & Little & Very much \\
\hline Cost & Rather much & Rather low \\
\hline Degrees of Intelligent & No & good \\
\hline
\end{tabular}

need many equipments and backup systems. In the design of different parts of this system, it is attempted to use from the latest engineering and research investigations. For example, the gas generator system in this system has a modern technology and its design is not limited just to compressed air capsules. Also, in hydrodynamic design of the gas-filled bag it is attempted to use the effective issues on reducing drag, including injection of gas into the fluid flow boundary layer. Also a prototype was designed and builds for rising of a mass from a finite depth. In Figure 9 some of sea- tests of the prototype are shown.

\section{References}

1. Nicholls J H (2007). Underwater equipment recovery, World Intellectual Property Organization (WIPO), Pub. No.: WO/2007/083078.

2. Tanaka S (2009). Deep sea water lift-up device, World Intellectual Property Organization (WIPO), Pub. No.: 05.02.2009.

3. Otterblad S, and Dovertie R (1985). Lifting Body for Diving, US patent number 4,498,408.

4. Yu C A, and Schoenberg R (2010). Deep sea mining riser and lift system, World Intellectual Property Organization (WIPO), Pub. No.: WO/2010/036278.

5. Horener S F (1985). Fluid Dynamic Lift, Hoerner Fluid Dynamics, 235-248..

6. Incropera F P, and DeWitt D P (1990). Fundamentals of Heat and Mass Transfer, John Wiley and Sons, New York, $145-180$.

7. Franklin G, and Powell J (1980). Digital Control of Dynamic Systems, Chapter 2, Addison-Wesley, 37-56.

8. Goodwin C, Graebe S et al. (2001). Control System Design, Chapter 3, Prentice-Hall, 127-153.

9. Haugen $\mathrm{F}$ (2010). Advanced Dynamics and Control, Chapter 4, TeachTech, 212-251.

10. Fox R W, Alan T M et al. (1998). Introduction to Fluid Mechanics, Chapter 2, vol 1, New York: John Wiley \& Sons, 78-90.

11. Schlichting H (1979) Boundary Layer Theory, Chapter XXV, McGraw-Hill, New York, 758-769.

12. Dicker K, and Windows A (2003). Apparatus for recovery of buried underwater cable/pipe, World Intellectual Property Organization (WIPO), Pub. No. WO/2003/101827.

13. Barton J (2007). Remotely operated, underwater nondestructive ordnance recovery system and method, World Intellectual Property Organization (WIPO), Pub. No.: $\mathrm{WO} / 2007 / 108820$. 